\title{
A Fuzzy Expert System for Industrial Location Factor Analysis
}

\author{
Aleksandar Rikalovic, Ilija Cosic \\ Department of Industrial Engineering and Management, Faculty of Technical \\ Sciences, University of Novi Sad, Trg Dositeja Obradovica 6, 21000 Novi Sad, \\ Serbia; e-mail: a.rikalovic@uns.ac.rs, ilijac@uns.ac.rs
}

\begin{abstract}
The identification of a new industrial location requires consideration of a complex set of factors in the decision making process. These factors are generally described with a number of different indicators, expressed in quantitative and/or qualitative ways, thus resulting in a nonlinear optimization problem. Besides, some of the input data are imprecise, incomplete or not totally reliable. Therefore, it is necessary to interpret, standardize and fuse data in specific factors suitable for comparison. To take into account all of these aspects above and allow for identification of an optimal solution by reasoning on available information, this paper proposes the use of an expert system for industrial location factor analysis. Management of uncertainty is an important issue in the design of expert systems, since data maybe indefinite, inaccurate and ambiguous. Fuzzy logic provides an approach to data fusion and reasoning for uncertain data by using the human expert knowledge. The proposed expert system is based on Fuzzy Inference Systems (FIS), which solve the nonlinear optimization problem by using the available knowledge. Results show that the proposed approach obtains accurate results in industrial location factor analysis, similar to those devised by experts of the field.
\end{abstract}

Keywords: expert system; fuzzy logic; fuzzy inference system (FIS); decision support system (DSS); industrial location; factor analysis

\section{Introduction}

One of the most important and far-reaching strategic decisions faced by industry managers is deciding where to locate new industrial facilities [1]. The industrial location problem can be represented as a selection process of potential sites in order to satisfy all applied to requirements in the best possible way. Industrial location decision making must consider a wide range of quantitative and qualitative factors in order to coordinate socio-economic benefits and environmental sustainability [2]. Besides, increasing complexity is undoubtedly a relevant characteristic of today's international economy with many variables affecting location decision making: this is therefore, becoming a key issue in the 
firm strategies [3]. Goals considered in the selection process may be non-linearly related to the factors thus leading to a nonlinear optimization problem with respect to the each goal [4].

In many situations, we cannot consider only one criterion because several conflicting objectives usually need to be considered in decision making [5]. Industrial location is therefore multi-objective [6] and multi-criteria problem [7]. Multi-criteria decision making (MCDM) techniques have been used to solve various facility location problems $[8,9]$. However, these techniques, assume data homogeneity, which is unrealistic in many decision making situations such as industrial location problems. To allow for comparing the various goals and avoid biases due data representation in MCDA it is necessary to normalize and standardize all input data in a range suitable for processing before applying the multi-criteria analysis $[10,11]$. Industrial location analysis traditionally uses qualitative and quantitative tools such as checklists, dimensional analysis evaluation techniques and multivariate statistical analysis to deal with multicriteria analysis $[12,13]$.

Unfortunately, the above approaches are not sufficient in today's rapidly changing and highly uncertain environment, where strategic decisions on industrial location have an extremely complex and imprecise nature [14]. Managers are in fact making difficult and important decisions concerning industrial locations on the weak base of imprecise information and incomplete knowledge [15]. Besides, traditionally data are collected and treated as directly-measurable quantities for location selection, even though may be affected by some uncertainty due to the measurement process [16]. However, several characteristics of the location problem can be described only in a qualitative way by using the natural language, which is intrinsically approximate and imprecise representation of the information [17]. The challenge is how to bring quantitative and qualitative (linguistic) data into the same analytic methodology [18]: applying fuzzy logic seems to be the most appropriate method to incorporate all of these factors in the strategic decision making [19].

The industrial location problem requires complex knowledge management and analysis. The need of an appropriate support to human decision makers is due to four kinds of limits: cognitive, economic, time and competitive demands [20]. Usually previous experience or expert knowledge is used to design decision support systems [21]. To develop an intelligent decision support system for industrial location factor analysis, we need a holistic view of the various factors as well as of data and knowledge management (reasoning techniques) based on an expert system.

To address all of the above aspects in a comprehensive, homogeneous framework, we propose a hierarchical technique, based on a fuzzy expert system, which uses a set of Fuzzy Inference Systems (FIS) to interpret, standardize and fuse heterogeneous data in order to estimate normalized industrial location factors. 
This paper is organized as follows: in Section 2, we summarize the industrial location process, the typical industrial location factors and data representation, pointing out the role of the fuzzy representation in the decision support systems. In Section 3 we present the innovative methodology for industrial location factor analysis. Section 4 presents the implementation of the methodology in Vojvodina, Serbia as the study case to show the implementation choices. Section 5 shows examples of experimental results, and Section 6 some derives conclusions and directions for future research.

\section{Background}

The industrial location selection process requires the analysis and the possible optimization of a complex set of factors involving economic, social, technical, environmental and political issues. Due to the complexity of the task, the site selection process is divided into two phases: selection of a macro-location (i.e., the municipality) followed by the selection of a micro-location (i.e., the specific location) [12]. Zelenovic [13] also distinguish macro and micro location and proposing process consisting of four phases: selection of continent, selection of country, selection of municipality, and finally selection of the specific location.

A large amount of information must be accumulated to aid in the decision-making process. Many of factors have to be considered in the industrial location selection process, as social and environmental aspects have received more emphasis in the process and are supported by legislations and regulations [22]. The number and the types of factors affecting the location selection vary in each case, and they often can be hundreds. The most commonly used industrial location factors are linked in Table 1 [23].

Table 1

Typical industrial location factors

\begin{tabular}{|l|l|}
\hline Grouped Factors & Factors \\
\hline Transportation & $\begin{array}{l}\text { Highway facilities, railroad facilities, waterway } \\
\text { transportation, airway facilities, trucking services, } \\
\text { shipping cost of raw material, cost of finished goods } \\
\text { transportation, shipping cost of raw material, warehousing } \\
\text { and storage facilities. }\end{array}$ \\
\hline Labor & $\begin{array}{l}\text { Low cost labor, attitude of workers, managerial labor, } \\
\text { skilled labor and wage rates, unskilled labor, unions, and } \\
\text { educational level of labor. }\end{array}$ \\
\hline Raw Materials & $\begin{array}{l}\text { Proximity to supplies, availability of raw materials, } \\
\text { nearness to component parts, availability of storage } \\
\text { facilities for raw materials and components and location of } \\
\text { suppliers. }\end{array}$ \\
\hline
\end{tabular}




\begin{tabular}{|l|l|}
\hline Markets & $\begin{array}{l}\text { Existing consumer market, existing producer market, } \\
\text { potential consumer market, anticipation of growth of } \\
\text { markets, marketing services, favorable competitive } \\
\text { position, population trends, location of competitors, future } \\
\text { expansion opportunities and size of market. }\end{array}$ \\
\hline Industrial Site & $\begin{array}{l}\text { Accessibility of land cost of industrial land, developed } \\
\text { industrial park, space for future expansion, availability of } \\
\text { lending institution, closeness to other industries. }\end{array}$ \\
\hline Utilities & $\begin{array}{l}\text { Attitude of utility agents, water supply, wastewater, cost } \\
\text { and quality, disposable facilities of industrial waste, } \\
\text { availability of fuels, cost of fuels, availability of electric } \\
\text { power and availability of gas. }\end{array}$ \\
\hline $\begin{array}{l}\text { Government } \\
\text { Attitude }\end{array}$ & $\begin{array}{l}\text { Building ordinances, zoning codes, compensation laws, } \\
\text { insurance laws, safety inspections and stream pollution } \\
\text { laws. }\end{array}$ \\
\hline Tax Structure & $\begin{array}{l}\text { Industrial property tax rates, state corporate tax structure, } \\
\text { tax free operations, and state sales tax. }\end{array}$ \\
\hline $\begin{array}{l}\text { Climate } \\
\text { and Ecology }\end{array}$ & $\begin{array}{l}\text { Amount snow fall, percent rain fall, living conditions, } \\
\text { relative humidity, monthly average temperature, air } \\
\text { pollution and ecology. }\end{array}$ \\
\hline Community & $\begin{array}{l}\text { Reputation of local authorities, colleges and research } \\
\text { institutions, attitude of community residents, quality of } \\
\text { schools, religious facilities, library facilities, recreational } \\
\text { facilities, attitude of community leaders, medical facilities, } \\
\text { hotels and motels. }\end{array}$ \\
\hline
\end{tabular}

Quantitative methods for data analysis can be used if all these data are quantitative. However, many data are qualitative in nature and presented in various linguistic forms [1]. From the viewpoint of incorporating qualitative factors in the location decision, the most widely used techniques are the weighted checklist approach [24] and the fuzzy logic [25].

In the literature, fuzzy logic has been used extensively in decision support systems, for strategic planning, in industrial organizations to model Fuzzy Inference System (FIS) [15]. Fuzzy Inference Systems are, in fact, methods for mapping an input space to an output space by using fuzzy logic [26]. Due their intuitive handling and simplicity, FIS have been applied in a wide range of fields, such as control, decision support, image processing, and expert systems [27]. The strength of FIS relies on two important characteristics. First, they are able to handle linguistic concepts. Second, they are universal approximators able to perform nonlinear mappings between inputs and outputs [28]. The fuzzy rules of the system make use of fuzzy linguistic terms described by membership functions [29]. These functions capture the human expert's conception of the linguistic terms. Fuzzy rules take the form IF (conditions) THEN (actions). Where conditions and actions are linguistic values applied to input and output variables respectively. 


\section{Methodology}

In this section we introduce an innovative methodology for industrial location analysis. The proposed expert system manages and explores the knowledge in this specific application by reasoning on a database of facts by means of suitable inference rules. Fuzzy logic is applied to the decision support system for factors analysis providing a formal methodology to capture valid patterns for uncertainty reasoning. The proposed comprehensive, homogeneous framework uses a set of Fuzzy Inference Systems to interpret, standardize and fuse heterogeneous data in order to estimate normalized industrial location factors.

The FIS for industrial location factor analysis is divided into three main components: the fuzzifier, the knowledge management and the defuzzifier (Figure 1). The fuzzifier and the defuzzifier convert external information in fuzzy quantities and vice versa. The knowledge management uses the fuzzy rules of the knowledge base that allows for approximate reasoning [30].

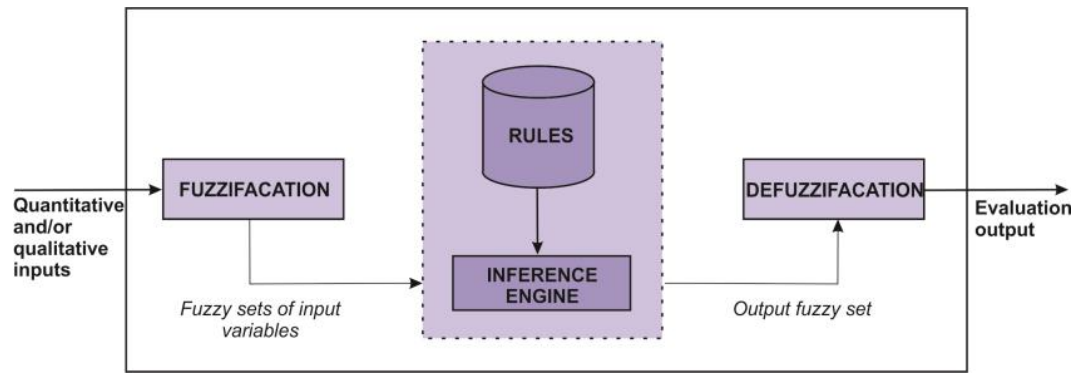

Figure 1

Fuzzy Expert System

For fuzzification of quantitative variables we used trapezoidal membership functions while triangular membership functions are used for qualitative inputs [31]. To interpret the inputs we defined boundaries and level of uncertainty in the membership functions.

The rule based system is provided by the expert of the field to combine and process fuzzy data and derive the desired knowledge about the envisioned environment. We developed suited fuzzy rules to generate normalized outputs for the industrial location selection problem.

In the literature, there are different approaches for the FIS design and implementation. The Mamdani's fuzzy inference method [31] is the most used. This method is characterized by the following fuzzy rule schema:

$$
\text { IF ( } x \text { is } A \text { ) THEN ( } y \text { is } B \text { ) }
$$

where $A$ and $B$ are fuzzy sets defined on the input and output domains, respectively. The if-part of the rule " $x$ is $A$ " is called the antecedent, while the 
then-part of the rule " $y$ is $B$ " is called the consequent [32]. If there are more input variables in the antecedent they are joined by the OR and AND operators.

In Mandami's FIS, the antecedents and the consequents of the rules are expressed as linguistic constraints [31]. As a consequence, this kind of FIS provides an intuitive technique to represent the knowledge base, which is easy to understand and maintain. This approach is therefore, widely used in decision support systems [34].

In the expert system proposed in this paper all designed FIS are based on the same defuzzification module, where output is normalized and represented in the range $[0,10]$ suitable for multi-criteria analysis. The output is given by a set of five triangular membership functions representing the linguistic properties: insufficient, regular, satisfactory, good and excellent (Figure 2). In the final step of the defuzzification process we used the centroid rule [31].

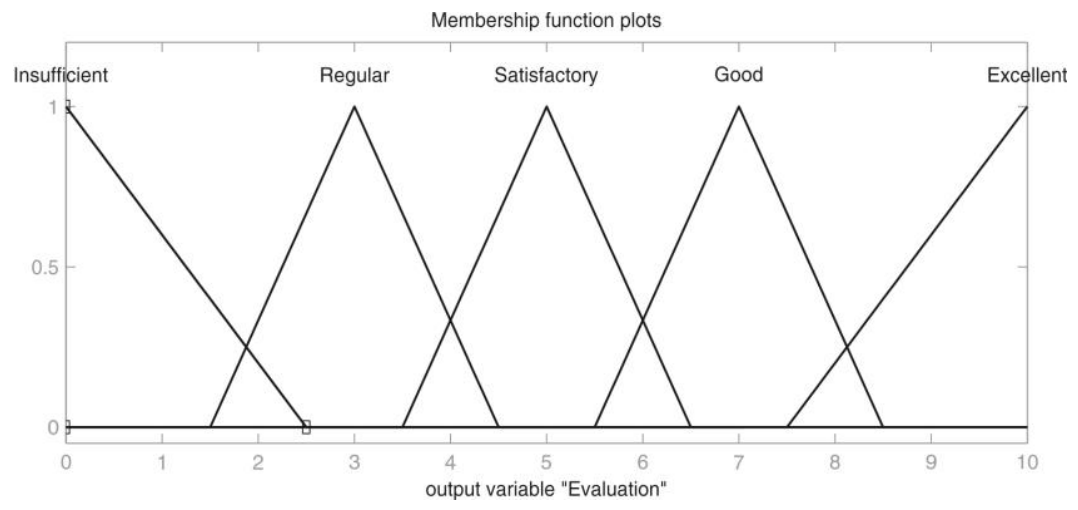

Figure 2

Triangular MFs

The FIS's of the proposed expert system for industrial location factor analysis, has been implemented and tested by using MATLAB, by exploiting the fuzzy descriptions and processing made available by the Fuzzy System Toolbox.

\section{Implementation}

In this section we describe the implementation of the proposed fuzzy expert system for industrial location analysis whose general structure has been introduced in Section 3. To test the efficiency and the effectiveness of the proposed approach we implemented the Fuzzy Inference Systems for the study case of Vojvodina, a region in Serbia. We focused on four typical industrial location factors for municipality selection: airway facilities, reputation and efficiency of local authorities, utilities and ecology. We designed four Fuzzy 
Inference Systems to interpret, standardize and fuse heterogeneous data, in order to estimate the normalized industrial location factors. In the following we will analyze each of the FIS systems.

\subsection{Airway Facilities}

To design Fuzzy Inference System for the factor airway facilities, we used one input variable: distance from the airport. We considered this quantitative input variable defined in the range from 0 to $150 \mathrm{~km}$. Linguistically, we represented it with five triangular membership functions: very close, close, acceptable, faraway and very far away (Figure 3).

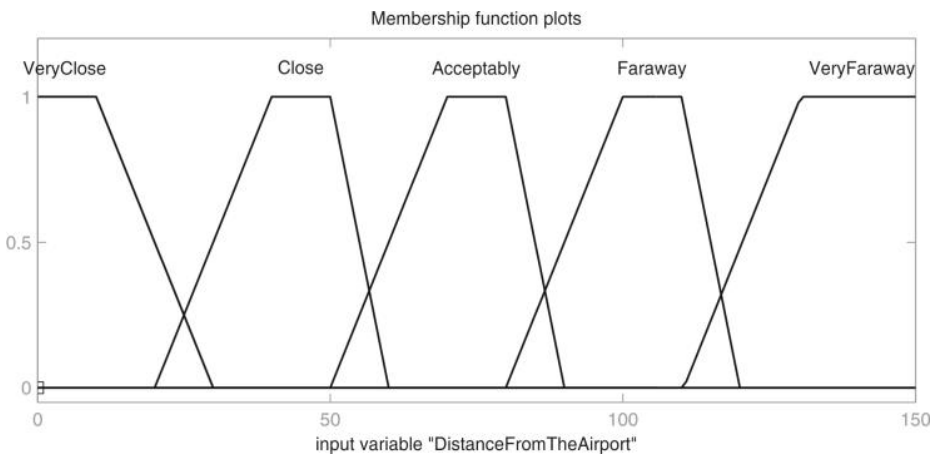

Figure 6

Membership functions for input variable distance from the Airport

The knowledge base for the factor airway facilities includes the following IFTHEN rules:

1) IF (DistanceFromTheAirport is VeryClose) THEN (Evaluation is Excellent);

2) IF (DistanceFromTheAirport is Close) THEN (Evaluation is Good);

3) IF (DistanceFromTheAirport is Acceptably) THEN (Evaluation is Satisfactory);

4) IF (DistanceFromTheAirport is Faraway) THEN (Evaluation is Regular);

5) IF (DistanceFromTheAirport is VeryFaraway) THEN (Evaluation is Insufficient).

In Figure 4 we report the output resulting from the application of these IF-THEN rules, with the membership function given above. 


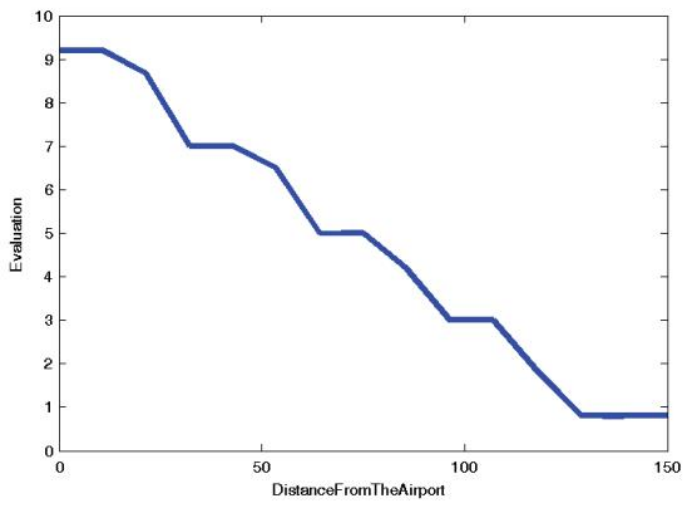

Figure 4

Output surface for the FIS airway facilities

\subsection{Reputation and Efficiency of Local Authorities}

To design Fuzzy Inference System for factor reputation and efficiency of local authorities we used two input variables: number of investment and business environment. For the quantitative input variable number of investment we defined range from 0 to 20 investments. Linguistically, we represented it with triangular membership functions: very small number, small number, average number, high number and very high number (Figure 5).

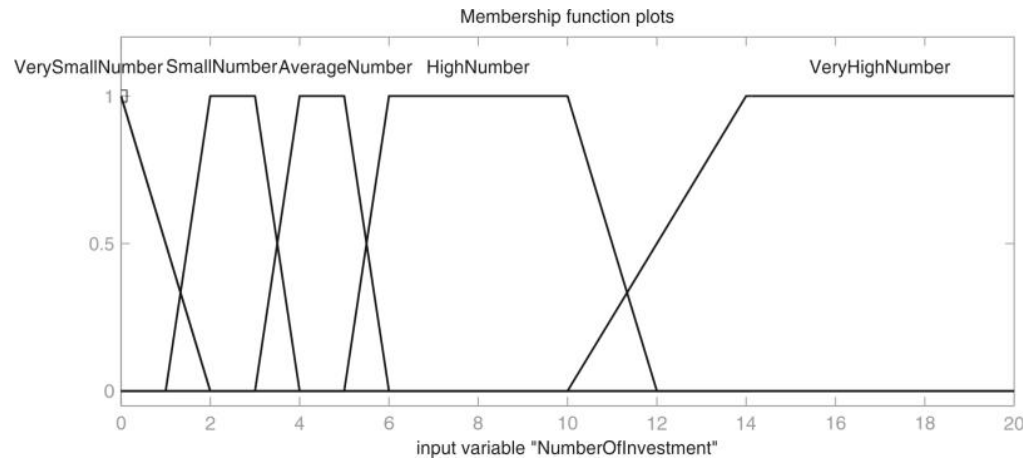

Figure 5

Membership functions for input variable number of investment

For the qualitative input variable business environment are defined in the range from 1 to 5 and linguistically represented trapezoidal membership functions: without certificate, in the certification process, certificate candidate and certified (Figure 6). 


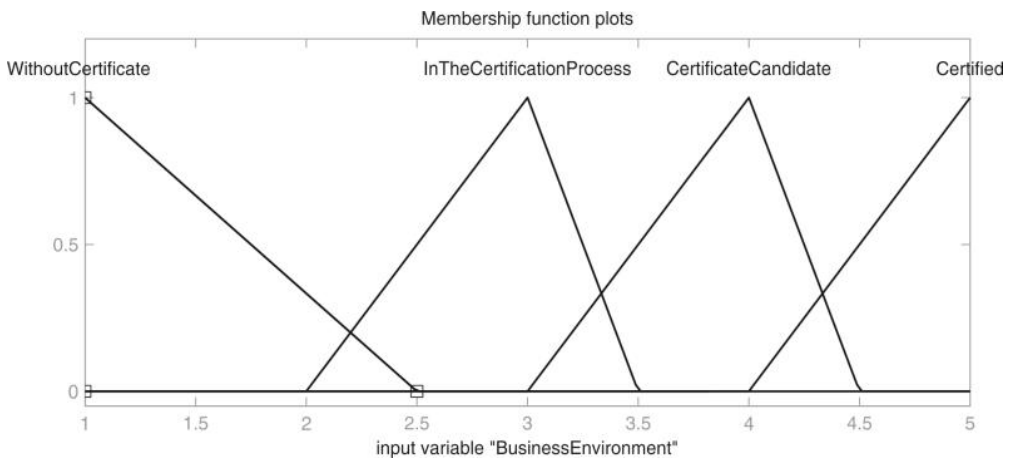

Figure 6

Membership functions for input variable business environment

The knowledge base for the factor reputation and efficiency of local authorities includes the following IF-THEN rules joined by AND operators:

1) IF (NumberOfInvestment is VerySmallNumber) AND (BusinessEnvironment is WithoutCertificate) THEN (Evaluation is Insufficient);

2) IF (NumberOfInvestment is SmallNumber) AND (BusinessEnvironment is InTheCertificationProcess) THEN (Evaluation is Regular);

3) IF (NumberOfInvestment is AverageNumber) AND (BusinessEnvironment is CertificateCandidate) THEN (Evaluation is Satisfactory);

4) IF (NumberOfInvestment is HighNumber) AND (BusinessEnvironment is Certified) THEN (Evaluation is Good);

5) IF (NumberOfInvestment is VeryHighNumber) AND (BusinessEnvironment is Certified) THEN (Evaluation is Excellent);

6) IF (NumberOfInvestment is VeryHighNumber) AND (BusinessEnvironment is CertificateCandidate) THEN (Evaluation is Excellent);

7) IF (NumberOfInvestment is VeryHighNumber) AND (BusinessEnvironment is InTheCertificationProcess) THEN (Evaluation is Good);

8) IF (NumberOfInvestment is VeryHighNumber) AND (BusinessEnvironment is WithoutCertificate) THEN (Evaluation is Satisfactory);

9) IF (NumberOfInvestment is VerySmallNumber) AND (BusinessEnvironment is InTheCertificationProcess) THEN (Evaluation is Insufficient);

10) IF (NumberOfInvestment is SmallNumber) AND (BusinessEnvironment is WithoutCertificate) THEN (Evaluation is Regular);

11) IF (NumberOfInvestment is VerySmallNumber) AND (BusinessEnvironment is Certified) THEN (Evaluation is Regular); 
12) IF (NumberOfInvestment is VerySmallNumber) AND (BusinessEnvironment is CertificateCandidate) THEN (Evaluation is Regular);

13) IF (NumberOfInvestment is HighNumber) AND (BusinessEnvironment is CertificateCandidate) THEN (Evaluation is Good);

14) IF (NumberOfInvestment is SmallNumber) AND (BusinessEnvironment is CertificateCandidate) THEN (Evaluation is Satisfactory);

15) IF (NumberOfInvestment is SmallNumber) AND (BusinessEnvironment is Certified) THEN (Evaluation is Satisfactory).

In Figure 7 we report the output resulting from the application of these IF-THEN rules, with the membership function given above.

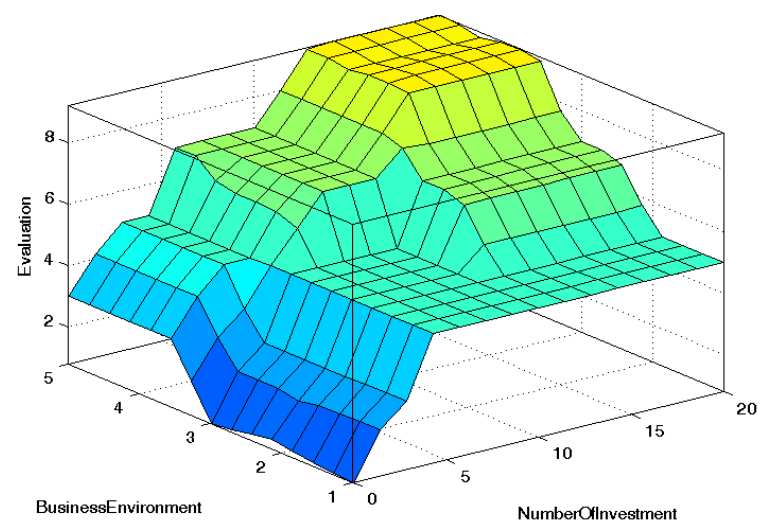

Figure 7

Output surface for the FIS reputation and efficiency of local authorities

\subsection{Utilities}

To design a Fuzzy Inference system for the factor utilities, we used four input variables: industrial property tax, price of water, price of the wastewater and price of garbage. For quantitative variable input industrial property tax we defined range from 0 to 150 (RSD), for price of water and price of the wastewater range from 0 to $150\left(\mathrm{RSD} / \mathrm{m}^{3}\right)$ and for price of garbage range from 0 to 50 $\left(\mathrm{RSD} / \mathrm{m}^{3}\right)$. Linguistically, we represented it with five triangular membership functions: very small price, small price, acceptable price, high price and very high price (Figures 8, 9, 10, 11). 


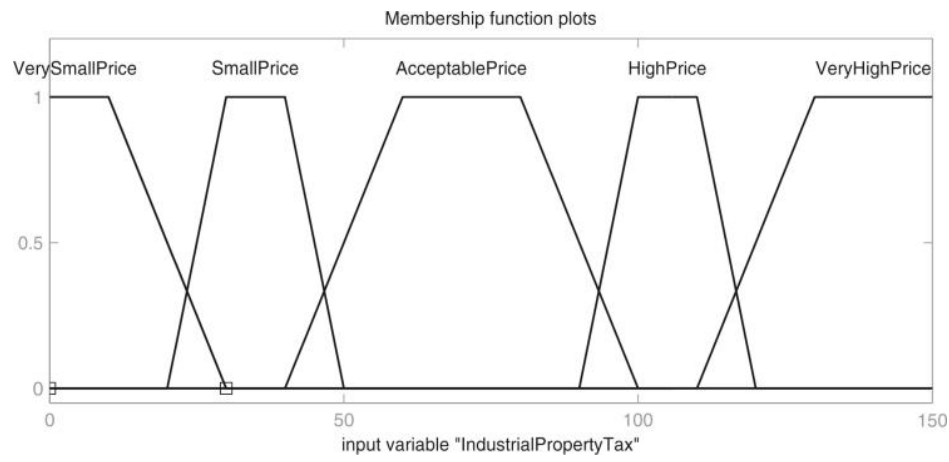

Figure 8

Membership functions for input variable industrial property tax

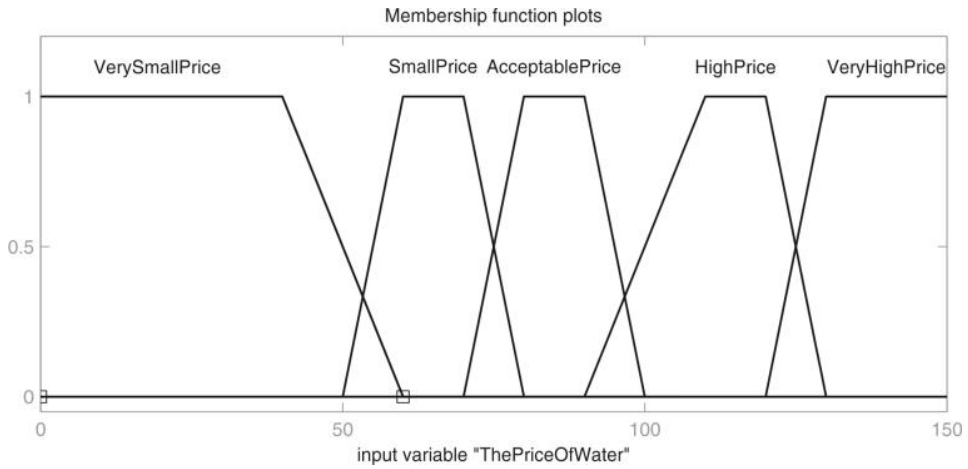

Figure 9

Membership functions for input variable price of water

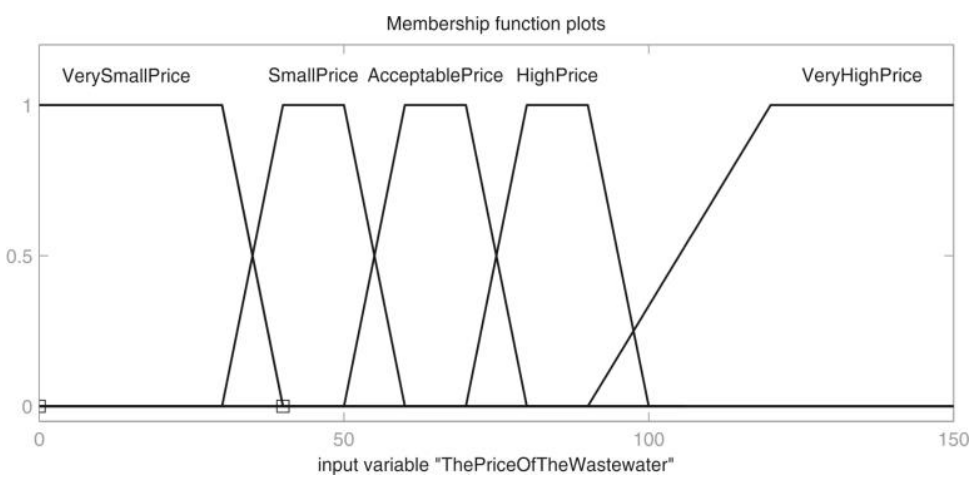

Figure 10

Membership functions for input variable price of the wastewater 


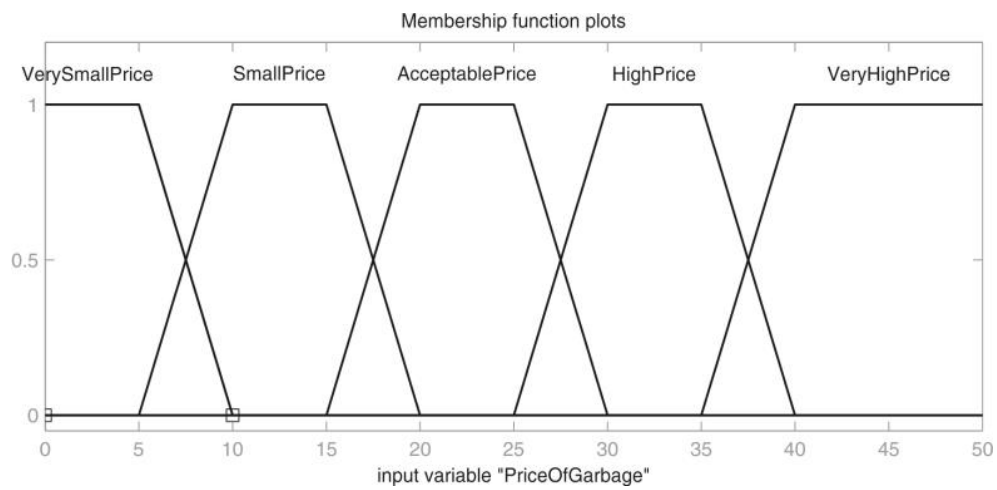

Figure 11

Membership functions for input variable price of garbage

The knowledge base for the factor utilities includes the following IF-THEN rules joined by OR operators:

1) IF (IndustrialPropertyTax is VerySmallPrice) OR (ThePriceOfWater is VerySmallPrice) OR (ThePriceOfTheWastewater is VerySmallPrice) OR (PriceOfGarbage is VerySmallPrice) THEN (Evaluation is Excellent);

2) IF (IndustrialPropertyTax is SmallPrice) OR (ThePriceOfWater is SmallPrice) OR (ThePriceOfTheWastewater is SmallPrice) OR (PriceOfGarbage is SmallPrice) THEN (Evaluation is Good);

3) IF (IndustrialPropertyTax is AcceptablePrice) OR (ThePriceOfWater is AcceptablePrice) OR (ThePriceOfTheWastewater is AcceptablePrice) OR (PriceOfGarbage is AcceptablePrice) THEN (Evaluation is Satisfactory);

4) IF (IndustrialPropertyTax is HighPrice) OR (ThePriceOfWater is HighPrice) OR (ThePriceOfTheWastewater is HighPrice) OR (PriceOfGarbage is HighPrice) THEN (Evaluation is Regular);

5) IF (IndustrialPropertyTax is VeryHighPrice) OR (ThePriceOfWater is VeryHighPrice) OR (ThePriceOfTheWastewater is VeryHighPrice) OR (PriceOfGarbage is VeryHighPrice) THEN (Evaluation is Insufficient).

In Figure 12 we report the output resulting from the application of these IF-THEN rules, with the membership functions given above. 


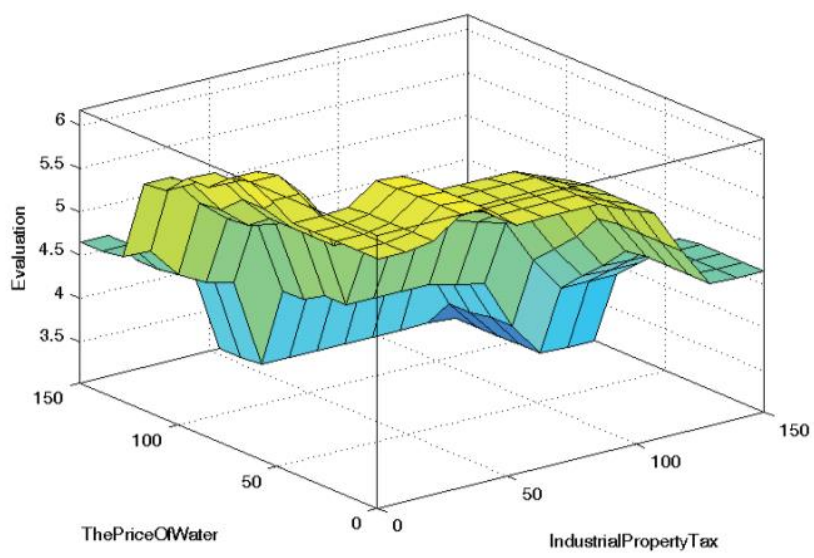

Figure 12

Output surface for the FIS utilities

\subsection{Ecology}

To design the fuzzy inference system for the factor ecology, we used one input variable: environmental assessment. We considered this quantitative input variable defined in the range from 1 to 4 . Linguistically, we represented it with five membership functions: degraded environment, endangered environment, quality environment and very quality environment (Figure 13).

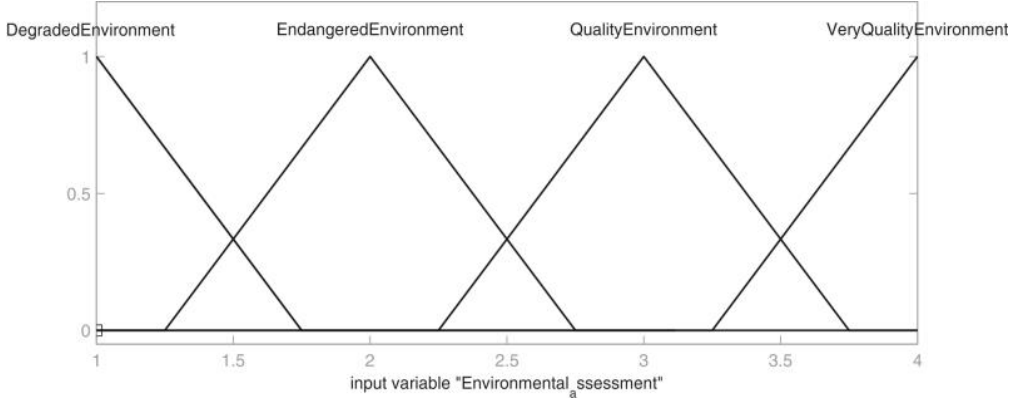

Figure 13

Membership functions for input variable Environmental assessment

Knowledge Base for the factor ecology includes the following IF-THEN rules:

1) IF (EnvironmentalAssessment is DegradedEnvironment) THEN (Evaluation is Insufficient);

2) IF (EnvironmentallAssessment is EndangeredEnvironment) THEN (Evaluation is Regular); 
3) IF (EnvironmentalAssessment is QualityEnvironment) THEN (Evaluation is Good);

4) IF (EnvironmentalAssessment is VeryQualityEnvironment) THEN (Evaluation is Excellent).

In Figure 7 we report the output resulting from the application of IF-THEN rules, with the membership functions given above.

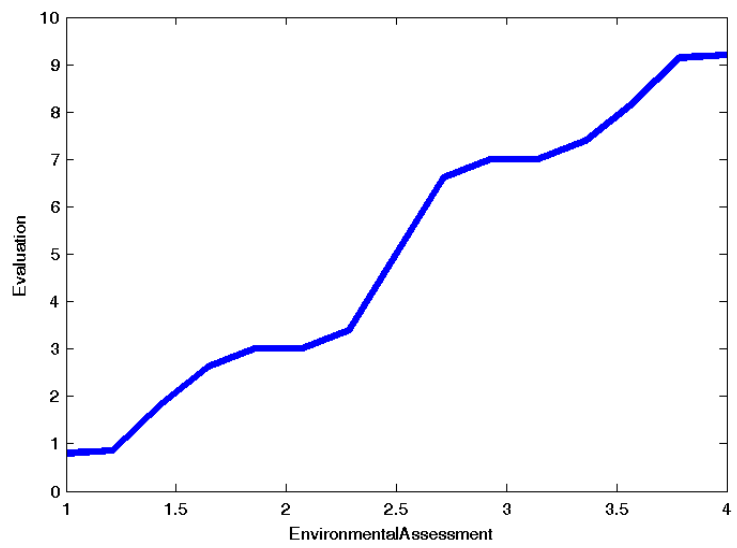

Figure 14

Output surface for the FIS Ecology

\section{Experimental Results}

In this section we report the final results produced by the use of the fuzzy expert system for industrial location analysis. By combining the IF-THEN rules we obtain the evaluation of the each municipality and its suitability as industrial location, by considering the factors described in Section 4 . We provided results for all the 45 municipalities of the study case. The outputs are standardized in the range $[0,10]$, where 0 means not suitably and 10 full suitability for industrial location. In Figure 15 we show example of the inference rules and the results for the factor airway facilities for Pecinci municipality. The evaluation of the suitability for the Pecinci municipality is between good and excellent with grade 7.98. In Figure 16 show an example for factor reputation and efficiency of local authorities for Indjija municipality. The Evaluation of the suitability for the Indjija municipality is excellent with grade 9.2. 

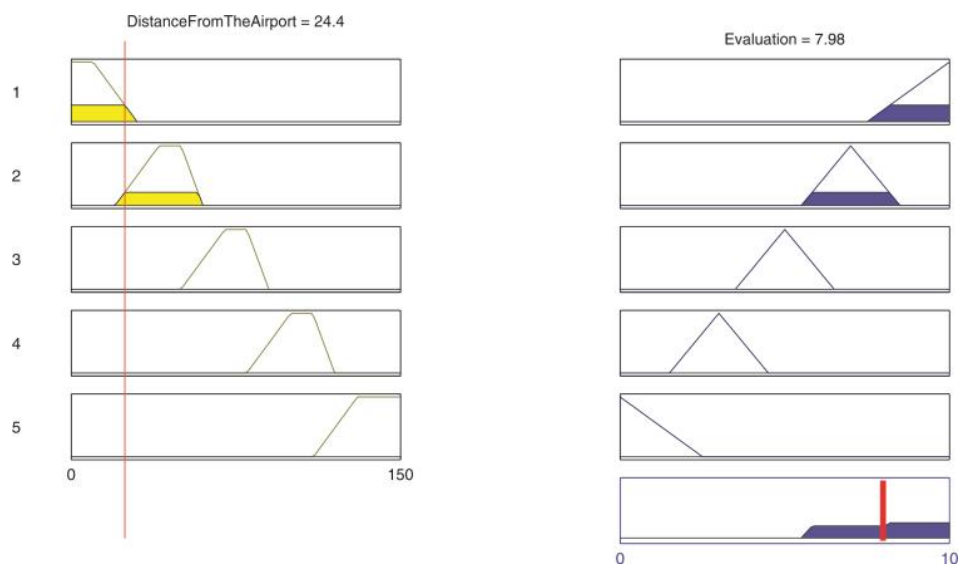

Figure 15

Combination of the defined rules and results for the factor airway facilities for Pecinci municipality

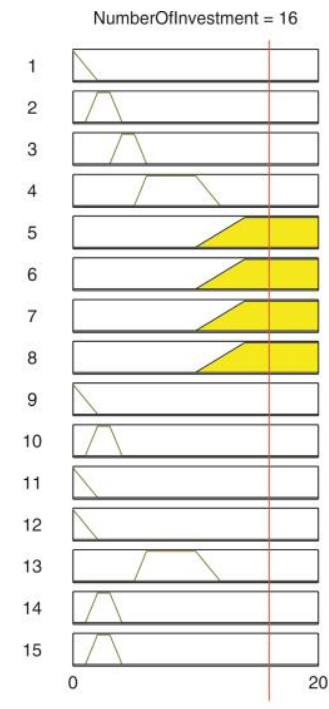

Figure 16

BusinessEnvironment $=4$

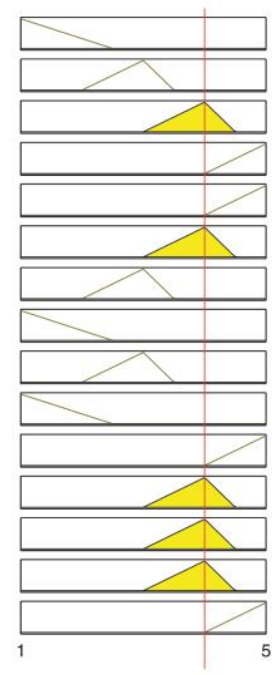

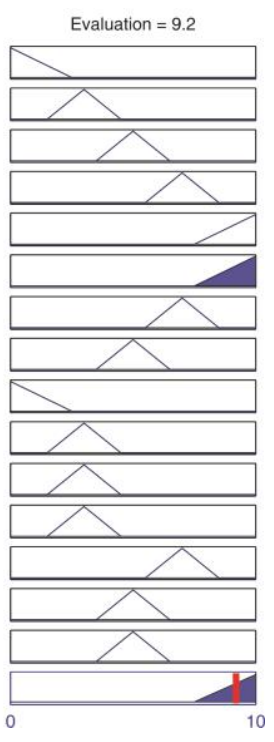

Combination of the defined rules and results for the reputation and efficiency of local authorities for Indjija municipality

In Figure 17 we show combination of the defined rules and results for the factor utilities for Zrenjanin municipality as example. Evaluation of suitability for Zrenjanin municipality is between satisfactory and good with grade of 5.59. In Figure 18 we show example of output results for the factor ecology for Kikinda municipality. Evaluation of suitability for Kikinda municipality is insufficient, with grade 0.8 . 

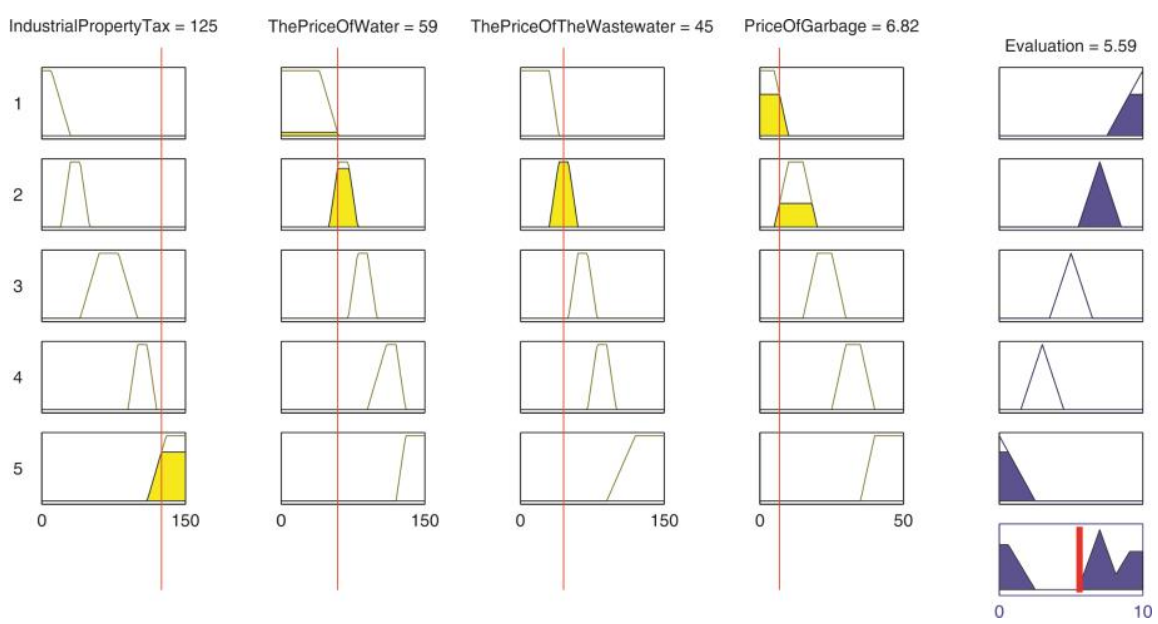

Figure 17

Combination of the defined rules and results for the factor utilities for Zrenjanin municipality
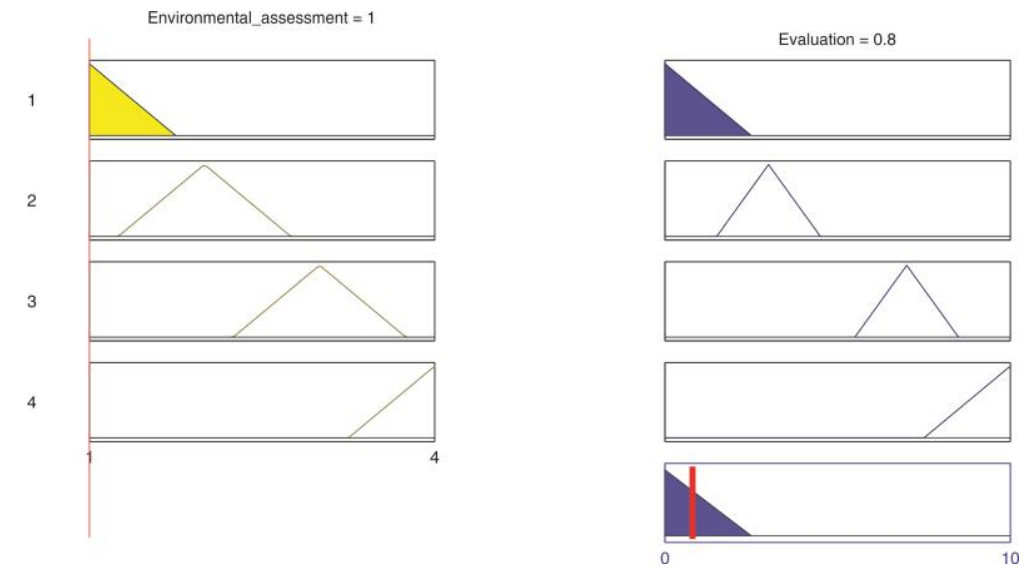

Figure 18

Combination of the defined rules and results for the factor ecology for Kikinda municipality

All results for the 45 municipalities were obtained in the same manner as in the given examples and show the different suitability of the municipality for each various factors.

\section{Conclusion}

An expert system for industrial location factor analysis, composed of various Fuzzy Inference Systems, addressing specific aspects, has been developed to manage uncertainty, standardization and fusion of data in a homogeneous framework. We used fuzzy logic in the decision support system for factors analysis as methodology to capture valid patterns for reasoning about uncertainty 
of quantitative and qualitative data. The presented methodology can be used for various factors and in different regions by tailoring the membership functions and the IF-THEN rules to the specific case.

The FIS for comprehensive industrial location factor analysis presented in this paper has been tested: results are equivalent to those derived by experts in the field. In further research, we will explore the connection between multi-criteria decision analysis and fuzzy expert systems.

\section{References}

[1] R. Bhatnagara, A. S. Sohalb, Supply Chain Competitiveness: Measuring the Impact of Location Factors, Uncertainty and Manufacturing Practices, Technovation, No. 25, pp. 443-456, 2005

[2] M. Reisi, L. Aye, A. Soffianian, "Industrial Site Selection by GIS in Isfahan," $19^{\text {th }}$ Iran International Conference on Geoinformatics, 2011

[3] L. A. Sabater, A. A. Tur, J. M. Navarro, Industrial Location, Spatial Discrete Choice Models and the Need to Account for Neighbourhood Effects, $3^{\text {rd }}$ World Conference of the Spatial Econometrics Association, Barcelona Spain, 8-10 July 2008

[4] Z. M. Shen, C. Coullard, M. S. Daskin, A Joint Location-Inventory Model. Transportation Science 37(1), pp. 40-55, 2003

[5] D. Queiruga, G. Walter, J. G. Bention, and T. Spengler, "Evaluation of Sites for the Location of WEEE Recycling Plants in Spain," Waste Management, Vol. 11, pp. 181-190, 2006

[6] S. Carver, Integrating Multi-Criteria Evaluation with Geographical Information Systems. International Journal of Geographical Information Systems, 5, pp. 321-339, 1991

[7] W. Atthirawong and B. MacCarthy, "An Application of Analytical Hierarchy Process to International Location Decision Making," presented at $7^{\text {th }}$ Annual Cambridge International Manufacturing Symposium: Restructuring Global Manufacturing, Cambridge. England: University of Cambridge, pp. 1-18, 2002

[8] M. Badri, "Combining the Analytic Hierarchy Process and Goal Programming for Global Facility Location- Allocation Problem", Int. J. Production Economics, 62, pp. 237-248, 1999

[9] J. Korpela, and M. Tuominen, "A Decision Aid in Warehouse Site Selection”, Int. J. Production Economics, 45, pp. 169-180, 1996

[10] H. Voogd, Multicriteria Evaluation for Urban and Regional Planning. Pion, Ltd., London, 1983

[11] J. R. Eastman, Idrisi for Windows, Version 2.0: Tutorial Exercises, Graduate School of Geography - Clark University, Worcester, MA., 1997 
[12] D. Zelenovic, "Location of Production Systems," in The Design of Production Systems, $2^{\text {nd }}$ ed. Novi Sad: Faculty of Technical Sciences, pp. 373-394, 2003

[13] U. Bankhofer, Industrial Location Management. Wiesbaden: German university-Verlag, 2001

[14] Ghazinoory, S. Zadeh and Memariani, A. Fuzzy SWOT Analysis. Journal of Intelligent \& Fuzzy Systems, No. 18, pp. 99-108, 2007

[15] I. Rawabdeha, A. Al-Refaie and H. Arabiyatd, Developing a Fuzzy Logic Decision Support System for Strategic Planning in Industrial Organizations, Advanced Technology \& Science, IJISAE, 1(2), pp. 14-23, 2013

[16] P. Rezaei, K. Rezaie, S. N. Shirkouhi and M. R. J. Tajabadi, Application of Fuzzy Multi-Criteria Decision Making Analysis for Evaluating and Selecting the Best Location for Construction of Underground Dam, Acta Polytechnica Hungarica, Vol. 10, No. 7, 2013

[17] R. Tanscheit, Sistemas Fuzzy. Rio de Janeiro: Departamento de Engenharia Elétrica, PUC- Rio, 2004

[18] J. Malczewski, GIS and Multicriteria Decision Analysis, John Wiley and Sons, Toronto, 1999

[19] K. Culo and Skendrovic, V. A Fuzzy Logic Approach to Decision Making. A proceeding of $7^{\text {th }}$ OTM Conference Preliminary Program, Croatia, 2006

[20] C. W. Holsapple and A. B. Whinston, Decision Support Systems: A Knowledge-based Approach, West Publishing Company, Minneapolis, 1996

[21] N. E Matsatsinis, M. Doumpos and C. Zopounidis, Knowledge Acquisition and Representation for Expert Systems in the Field of Financial Analysis, Expert Systems With Applications, Vol. 12, No. 2, pp. 247-262, 1997

[22] R. L. Keeney, Siting Energy Facilities. New York: Academic Press, 1980

[23] M. A. Badri, "Dimensions of Industrial Location Factors: Review and Exploration," Jornal of Business and public affairs Volume 1, Issue 2, 2007

[24] R. Tanscheit, Sistemas Fuzzy. Rio de Janeiro: Departamento de Engenharia Elétrica, PUC- Rio, 2004

[25] C. Dhaya and G. Zayaraz, Pondicherry Engineering College, Puducherry, International Journal of Advanced Science and Technology Vol. 49, December, 2012

[26] G. Chen, Introduction to Fuzzy Sets, Fuzzy Logic, and Fuzzy Control Systems. Hoboken, NJ: CRC Press, 2000

[27] T. J. Ross, Fuzzy Logic with Engineering Applications, $2^{\text {nd }}$ ed. Chichester: Wiley, 2004 
[28] G. Serge (2001) Designing Fuzzy Inference Systems from Data: Interpretability oriented Review, IEEE Transactions on Fuzzy Systems, Vol. 9, No. 3, pp. 426-442, 2001

[29] T. J. Ross., Fuzzy Logic with Engineering Applications, International Edition, McGraw-Hill, Inc, 1997

[30] E. Czogala and J. Leski, Fuzzy and Neuro-Fuzzy Intelligent Systems, ser. Studies in Fuzziness and Soft Computing. Springer, Vol. 47, 2000

[31] E. Mamdani and S. Assilian, "An Experiment in Linguistic Synthesis with a Fuzzy Logic Controller,” Int. Journ. of Man-Machine Studies, Vol. 7, No. 1, pp. 1-13, 1975

[32] A. Provotar, A. Lapko, and A. Provotar, "Fuzzy Inference Systems and their Applications," Cybernetics and Systems Analysis, Vol. 49, No. 4, pp. 517-525, 2013

[33] L. A. Zadeh, "Toward a Theory of Fuzzy Information Granulation and its Centrality in Human Reasoning and Fuzzy Logic," Fuzzy Sets and Systems, Vol. 90, No. 2, pp. 111-127, 1997

[34] R. Abrahart, L. See, and D. Solomatine, Building Decision Support Systems Based on Fuzzy Inference, in Practical Hydroinformatics, ser. Water Science and Technology Library, Eds., Vol. 68, pp. 215-228, 2008 